\title{
Cambios en la banca y su impacto en las empleadas del sector financiero en México
}

\author{
Ma Luisa GonZÁLEz MARÍN \\ Instituto de Investigaciones Económicas \\ Universidad Nacional Autónoma de Méxic \\ gmarin@unam.mx
}

Recibido: 12.10.2011

Aceptado: 25.11.2011

\section{RESUMEN}

El objetivo de este artículo es estudiar los efectos que han tenido sobre las trabajadoras los cambios en las formas de organización del trabajo en la banca. Para ello, recurrimos a las estadísticas sobre el empleo y a entrevistas a empleadas de este sector. El resultado obtenido muestra que los cambios provocaron un deterioro de las condiciones de trabajo de las mujeres acompañado por una profundización de la discriminación de género.

Palabras clave: Banca, empleadas, discriminación, cambios, empleos.

\section{Changes in banking and its impact on financial sector employees in Mexico}

\begin{abstract}
The objective of this article is to study the effects that have been working on changing forms of work organization on the bench. To do this, we turn to employment statistics and interviews with employees of this sector. The result shows that the changes led to a deterioration of working conditions of women accompanied by a deepening of gender discrimination.
\end{abstract}

Key words: Banking, women employment, discrimination, changes.

El objetivo de este artículo es señalar los cambios en el sistema bancario y su impacto en las condiciones laborales de sus empleadas. Las transformaciones en la organizacióndel trabajo no es un fenómeno regional sino universal, los modelos de organización se han aplicado lo mismo en México, que en Inglaterra, Colombia, o Estados Unidos, casi ningún país escapa a estos cambios. El resultado de todo ello ha sido un deterioro en la situación de los trabajadores de la banca y especialmente en las mujeres.

Este tipo de empleados que, antaño, sentían orgullo de pertenecer a tan selecto conjunto de asalariados, ahora están concientes que son parte de un grupo que tiende a la homogeneidad. En el cual predomina una escasa capacitación y una acelera- 
da rotación de personal, dando lugar al predominio de trabajadores improvisados que ofrecen un mal servicio porque apenas empiezan a conocer los instrumentos financieros de la banca y ya ocupan el puesto de ejecutivo. Según una gerente entrevistada, "los trabajadores de ahora son muy jóvenes no duran nada, son muy volátiles, porque les quieren enseñar en 2 meses lo que a mí me costo años, están locos”. (Alba)

Los privilegios que gozaron, muy por encima del resto, los fueron perdiendo conforme la banca pasó del Estado a los banqueros mexicanos y luego a los extranjeros. Con la globalización, los empleados se dividieron en tres grupos: cajeros, “ejecutivos” y administrativos. Los dos primeros con una tendencia a igualar tanto la disminución de sus prestaciones como el trabajo a realizar. Lo que ha dado pie al cambio de su manera de pensar; ahora se conciben más como parte de los asalariados y menos como parte de los privilegiados.

Los recortes, liquidaciones y retiro de empleados de la banca no son los únicos problemas que enfrentan, tienen además la pérdida de prestaciones, la inestabilidad en el empleo y la disminución de sus ingresos, así como las modificaciones a las formas de contratación.

Los problemas señalados se presentan para todos los trabajadores, sean hombres o mujeres. Sin embargo, la condición de las mujeres en la sociedad patriarcal, profundiza la inequidad y la discriminación; ellas tendrán que seguir ocupándose de las tareas del hogar y padeciendo el trato sexista de compañeros y clientes en el centro de trabajo.

Si bien, esta situación no es novedosa, sí se profundizó en los años noventa cuando entró de lleno la globalización, cuando la expansión mundial del capital financiero dominó a las actividades productivas. "Nuestra tesis es de que la globalización, con todas sus características, se diferencia de otras épocas de la historia del capitalismo por el predominio del capital especulativo parasitario (forma particular más concreta del capital que devenga interés) a escala mundial, sobre el capital productivo" (Carcanholo y Nakatani, 2001: 9).

Un capital cuya función principal ha dejado de ser el préstamo crediticio para el fomento de la producción y se ha convertido en uno que obtiene sus ganancias por medio de la especulación, capaz de moverse de un país a otro y poner a temblar la economía de cualquier país, como sucedió en 2010 con Grecia y en 2011 con la Unión Europea.

Este enorme poder del sistema bancario y financiero, cuyas transformaciones más importantes se presentan en los años noventa, implicaron para sus trabajadores cambios en sus condiciones de vida y trabajo. Con las nuevas funciones del capital financiero, los viejos sistemas de trabajo resultaron obsoletos, así se empezaron a presentar los despidos masivos, sólo sobrevivieron unos cuantos trabajadores; pos- 
teriormente se implantaron los nuevos requisitos para la contratación, flexibilidad en los horarios, las exigencias de un mayor nivel educativo, salarios según productividad y pérdida de prestaciones.

De ser uno de los sectores más favorecidos pasó a ser un sector con niveles de ingreso "medio", pero con condiciones de trabajo semejantes a las del resto de los trabajadores. Sus sindicatos fueron perdiendo fuerza, quedando sometidos a las directrices de los bancos. Los cambios se aceptaron, según opinión de los trabajadores, porque no existía otra opción.

¿Cómo afectaron estos cambios a las mujeres?

Para responder esta pregunta se decidió utilizar dos tipos de información, una cuantitativa y otra cualitativa. La primera basada en series estadísticas sobre el empleo y la segunda en entrevistas a empleadas de la banca. El propósito es darle voz a las protagonistas.

\section{LA SITUACIÓN LABORAL DEL EMPLEO FEMENINO EN EL SECTOR FINANCIERO}

Las características más sobresalientes del empleo femenino en la banca las podemos medir con base en los siguientes indicadores: ocupación, nivel educativo, ingreso salarial, tipo de contratación, edad, antigüedad y tipo de ocupación.

\section{OCUPACIÓN Y DESPIDOS}

Trabajar en el sector financiero supone cumplir con una serie de requisitos, uno de los más importantes es tener un nivel educativo de bachillerato o al menos algunos años de licenciatura. Sobre todo se solicitan hombres y mujeres jóvenes de buena presencia y dispuestos a comprometerse con los objetivos de la empresa.

Las modernas políticas aplicadas a la organización interna de la banca influyen directamente en el escaso aumento del personal ocupado. Por ejemplo, con la privatización de la banca se redujo personal, se calcula que de 1992 a 1995 se despidieron 33,000 empleados, de los cuales 13,000 eran mujeres. Durante la crisis de 2007 a 2009, las mujeres perdieron 13,371 empleos, mientras que los hombres sólo 4,576, lo que sin duda señala que en esta crisis las mujeres fueron las primeras en ser despedidas. El empleo se empezó a recuperar en 2010 y las más beneficiadas fueron las mujeres, según vemos en el cuadro 1. Sin embargo, BBVA (Bancomer) informa que de 2007 a 2009, las mujeres disminuyeron en 972, y en 2010 aumentaron en 853, en realidad no alcanzaron a recuperar los empleos perdidos. (BBVA Bancomer, 2009). 
$M^{a} L$. González Marín C Cambios en la banca y su impacto en las empleadas del sector financiero...

Cuadro 1

\begin{tabular}{|r|r|r|r|r|r|}
\hline \multicolumn{7}{|c|}{ Poblacion Ocupada } \\
\hline \multicolumn{7}{|c|}{ Servicios Financieros y de seguros } \\
\hline & Mujeres & Hombres & Total & Mujeres & Hombres \\
\hline $\mathbf{2 0 0 5}$ & 143252 & 159,066 & 307,242 & 47 & 52 \\
\hline $\mathbf{2 0 0 6}$ & 167296 & 190,829 & 362,564 & 46 & 53 \\
\hline $\mathbf{2 0 0 7}$ & 183382 & 215,779 & 403,620 & 45 & 53 \\
\hline $\mathbf{2 0 0 8}$ & 192010 & 209,270 & 405,836 & 47 & 52 \\
\hline $\mathbf{2 0 0 9}$ & 167176 & 211,203 & 385,673 & 43 & 55 \\
\hline $\mathbf{2 0 1 0}$ & 198997 & 218,247 & 423,072 & 47 & 52 \\
\hline FUENTE: INEGI. Encuesta nacional de ocupación y empleo. & \\
\hline
\end{tabular}

Una de las entrevistadas señala que hace seis meses, el banco donde trabaja, "liquidó personal administrativo, sin importar la antigüedad, los despidieron y después los contrato la empresa externa, se anuncia que viene otro recorte similar,”. La estrategia de la banca es empezar a despedir al personal administrativo y seguir con las empleadas de las sucursales. Se ofrecen retiros voluntarios o liquidaciones. De esa manera las personas con más de 15 años de trabajo se jubilarán con el $40 \%$ de su sueldo. (Lucy)

El despido está tan presente en las políticas del sector financiero que conviene citar su opinión al respecto:

"Un representante legal de Santander reveló que desde la renovación de los niveles directivos de los bancos en México, así como la llegada de nuevos jugadores, se inició una “depuración hormiga” de las plantillas laborales en cada institución. El objetivo, dijo, fue trasladar al personal de base (sindicalizado) al estatus de empleado de confianza, para disminuir o desparecer las prestaciones que por años fueron superiores a la ley, como utilidades por arriba del promedio, servicios médicos privados y préstamos” (Terra Laboral, 21 de febrero de 2008)

En términos generales en las contrataciones privan los mismo requisitos para hombres y mujeres (lo veremos más adelante), pero a las mujeres se les exige someterse a otro tipo de pruebas. Casi todas las entrevistadas coinciden en que una vez que pasan las pruebas psicosomáticas, las mujeres enfrentan un segundo filtro, el banco realiza una prueba de embarazo y sangre, además revisan si en su cuerpo hay piercings y tatuajes. Sólo que no encuentren ninguna de estas cosas son contratadas. El cumplimiento de estos requisitos es un práctica común en los bancos privados que operan en México.

Otra entrevistada señala:

“ En mi sucursal para contratarte no debes tener piercing, tatuajes, hijos y estar embarazada” y agrega "Por ejemplo, un matrimonio postuló al empleo como solteros, ocultaron a su hijo. Tiempo después se tuvo que decir la verdad: no fueron 
despedidos, sólo amonestados. Muchos de mis compañeros más jóvenes son padres de familia y lo ocultan”.

Según un líder entrevistado, "en el banco se valora mucho el trabajo fuera del horario laboral. La maternidad impide ciertas cuestiones laborales y eso las pone en desventaja. El sindicato tiene una participación muy limitada en las contrataciones. Se les hace un examen médico, queda en el misterio si al estar embarazada las contratan o no" (Rafael).

La reorganización de la banca, su posterior venta al capital extranjero y especialmente el diseño para desregularla afectaron a los empleados/as al cambiar las formas de organización del trabajo. Las principales transformaciones venían con la aplicación de los nuevos sistemas de contratación de personal y con la competencia entre las principales instituciones financieras.

\section{OCUPACIONES EN LA BANCA Y DISCRIMINACIÓN A LAS MUJERES}

Por décadas las mujeres en la banca han estado concentradas en las categorías de más baja calificación, como oficinistas y agentes de venta. En 2010, las primeras representaban el $48.4 \%$ del total. Son actividades en donde se reciben los salarios más bajos, según los rangos del sector financiero.

En el otro extremo de la jerarquía están los puestos de dirección y profesionistas, en ellos las mujeres se enfrentan con un sistema discriminatorio, que dificulta el ascenso. Estas dificultades, la mayoría de las veces, no se relaciona con la calificación sino con los obstáculos que representan los tareas domésticas y las responsabilidades del cuidado de la familia. Según las entrevistadas, un nombramiento de gerente en una sucursal implica una extensión de la jornada, elaborar planes de productividad para el resto de los “ejecutivos” y cajeros, reuniones después de la jornada y otras actividades. Algo imposible de cumplir si se tiene familia, las responsabilidades relacionadas con el hogar se transfieren a la abuela, empleada doméstica u otra persona. Aun cuando las mujeres no tengan familia, una vez contratadas, la banca las considera como personas que en el futuro tendrán hijos y por tanto responsabilidades, las cuales las obligarán a faltar al trabajo, ocupar su mente en otras cuestiones, es preferible mantenerlas en puestos de menor responsabilidad ejecutiva.

En la crisis, las mujeres en puestos de dirección tienden a ser despedidas en mayor proporción que los hombres. Un ejemplo del límite al ascenso femenino, lo tenemos en los datos del Informe Anual de BBVA Bancomer. 
$M^{a}$ L. González Marín $\quad$ Cambios en la banca y su impacto en las empleadas del sector financiero...

Cuadro 2

Igualdad de oportunidades

\begin{tabular}{|l|r|r|r|r|r|r|}
\hline $\begin{array}{l}\text { Núm. de empleados por año y } \\
\text { sexo }\end{array}$ & Hombres & Mujeres & Hombres & Mujeres & Hombres & Mujeres \\
\hline Cargo & \multicolumn{7}{|l|}{2007} & & & & \\
\hline $\begin{array}{l}\text { Comité Dirección y Directores } \\
\text { Corporativos }\end{array}$ & 59 & 2 & 59 & 1 & 59 & 1 \\
\hline Directivos & 278 & 38 & 264 & 37 & 257 & 36 \\
\hline Mandos medios & 1911 & 761 & 1990 & 828 & 1982 & 858 \\
\hline Especialistas & 2823 & 2435 & 2872 & 2502 & 2860 & 2471 \\
\hline Fuerza venta & 7171 & 6888 & 6646 & 6656 & 5710 & 5730 \\
\hline Puestos base & 5052 & 7782 & 4926 & 7743 & 4790 & 7850 \\
\hline
\end{tabular}

Fuente:BBVA Bancomer. Informe Anual 2009

En los más altos puestos, como el Comité de Dirección y Directores Corporativos las mujeres disminuyeron en un $50 \%$, eran dos y sólo permanece una, respecto a los Directivos también han ido disminuyendo, este es el techo de cristal que enfrentan las mujeres en su ascenso laboral. En este banco, el porcentaje de las mujeres en los dos últimos niveles representaba alrededor del $80 \%$ del total de mujeres ocupadas.

En 2009, de los 9 principales directivos de primer nivel de WV Bank en México, sólo hay una mujer, y en el Consejo Directivo no hay ninguna. En BANORTE de los 15 principales directivos sólo había dos mujeres. Aquí se observa con toda claridad el llamado "techo de cristal”, el ascenso femenino en la banca tiene su límite.

El mismo ejemplo de BBVA se reproduce en casi todos los demás, como ya vimos, las mujeres están concentradas en los empleos de más baja remuneración, en 2010 estaban en los puestos de oficinistas o técnicos el 65.3\%, como se observa en la gráfica 1.

Sin embargo, esta discriminación no es exclusiva de México, en la Gran Bretaña, de las mujeres ocupadas en la banca el 70\% eran empleadas de oficina y sólo 3\% directoras o tenían posición de mando. (McDowell, 2008). Como puede observarse el "techos de cristal”es también un fenómeno universal. 
Gráfica 1

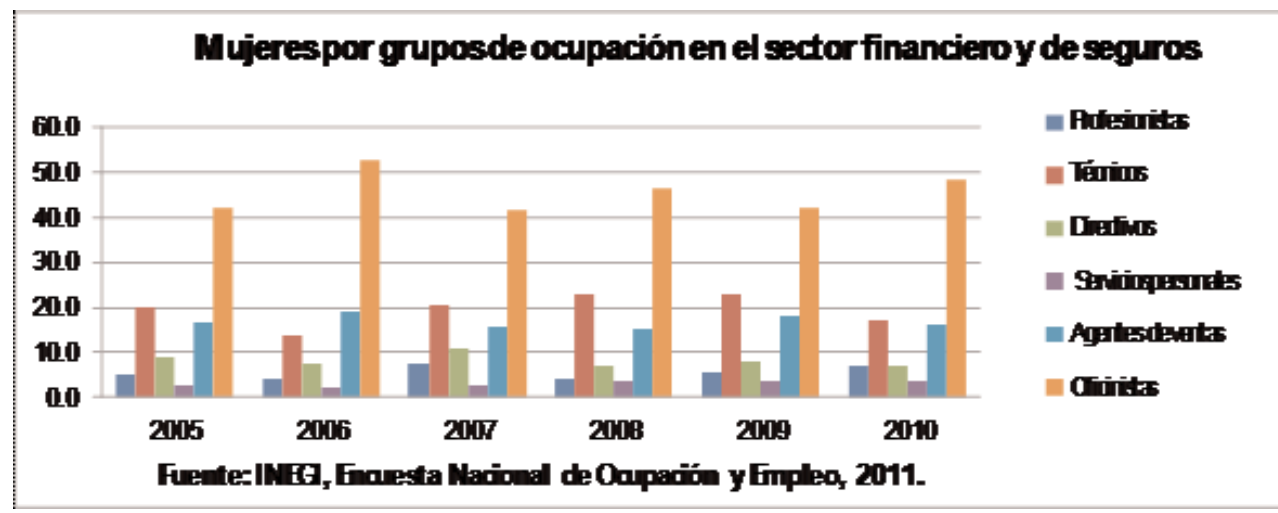

Según la opinión de los banqueros, los retos por los que atraviesa el sistema financiero en estos años de crisis requiere una modificación del tipo de trabajador. En adelante se demandará personal excelentemente calificado, experto en negocios y finanzas, además de técnicos y especialistas en información tecnológica. Las mujeres que están sobre todo en el ámbito administrativo irán perdiendo su puesto, su profesión se volverá obsoleta como pasó con las secretarias. La banca exigirá trabajadoras que conozcan sobre diversos servicios financieros y marketing. (Ilo, 2009).

Las exigencias de un mayor nivel educativo corresponde al "desarrollo tecnológico del sector y la reestructuración de las oficinas de plataformas de ventas, en oficinas cara al público y los centros del "back office” (Craig, 1996) . Las formas de contratación del personal en los bancos y en las compañías de seguros obedecen a las nuevos conceptos de venta, como el sistema Gestión de Recursos Humanos (GRH).

Con trabajadoras profesionistas capacitadas es más factible cumplir los requisitos del sistema (GHR). Deben ser personas capaces de aprobar todas las evaluaciones psicosomáticas, de preferencia pertenecer a determinado grupo social y tener una gran responsabilidad individual en cuanto a la formación y la promoción del servicio de carrera. (Craig, 1996) Proceso que se ilustra con la entrevista realizada a Claudia, "El banco para contratar prefiere mujeres con buena presentación, con piel blanca o trigueñas, sin rasgos indígenas, delgadas, profesionistas, solteras entre 18 y 35 años.”

En la contratación, las empleadas, además de estar cursando estudios de bachillerato o superiores debe tener "buena" apariencia. En otras palabras, estará sujeta a la discriminación por raza y por apariencia física. En opinión de una de las entrevistadas, "la discriminación por apariencia física está presente en el sector financiero, en mi banco, las menos agraciadas, con sobrepeso o algún rasgo fuera del canon de belleza, son enviadas a sucursales de la periferia urbana” (Lucrecia). 


\section{FORMAS DE CONTRATACIÓN, NIVEL EDUCATIVO Y ANTIGÜEDAD EN EL SECTOR FINANCIERO}

Las exigencias de mayor nivel educativo y de flexibilidad de horario no significa que los trabajadores/as tengan asegurado su empleo, como existía antes de la globalización, cuando el empleado podía planear su carrera laboral a largo plazo y asegurar su futuro por la vía de una pensión decorosa. Los tiempos han cambiado, los retos que enfrentan son diferentes, de acuerdo a la GRH, la carrera laboral a largo plazo ya no es conveniente para la empresa, calculan que en la banca la permanencia de los trabajadores debe durar alrededor de 7 años.

Para acabar con las permanencias prolongadas, se propone eliminar los salarios no ligados a la productividad, las prestaciones que obligan a los empleados a permanecer en la banca como son los préstamos para casa, auto, seguro de gastos médicos y otros.

Este tipo de prestaciones son eliminadas cuando se firman los nuevos contratos a corto plazo, renovables cada determinado número de meses y con tantos requisitos para obtener un salario mayor a 5 salarios mínimos (sm) que los empleados/as optan por renunciar a la banca. Según la entrevista de Ángela, “cada mes, cuando se cumplía mi contrato, me descansaban una semana, volvían a contratarme por otro mes y se repitió eso una y otra vez, hasta que renuncié, no pude aguantar tanta tensión”.

En 2010, el 49\% de las mujeres tenían una antigüedad de menos de un año a cinco, si agregamos el siguiente nivel, de 5 a 10 años, el porcentaje se eleva a $67 \%$. Lo anterior muestra una rotación de personal bastante acelerada. Tal parece que los objetivos de la banca sobre la carrera laboral de corto plazo han sido alcanzados. También encontramos una inequidad de género, porque las mujeres tienen una mayor concentración en los rubros de menor antigüedad. Por ello, aunque esa política se aplica para todo los empleados, las mujeres duran menos tiempo en el trabajo. Al cumplir las metas se evita la acumulación de años de trabajo y con ello la jubilación.

El problema es para quienes tienen más de 40 años, les será muy difícil encontrar trabajo en el sector financiero, tendrán que ocuparse como trabajadoras independientes, bajo una contratación de “comisión mercantil”. Según afirma una de las entrevistadas:

“Todas las trabajadoras incluyendo a las altas funcionarias después de los 40 años, ya no son buena imagen para el Banco, se les obliga al retiro voluntario, y su vida se les desmorona, caen en depresión porque cuando buscan trabajo en otras empresas les dicen "mejor vaya a cuidar a sus nietos" o que trabaje de forma independiente dando asesorías de crédito, Afores o seguros de vida, pero sólo se les permite esa actividad hasta los 55 años, después "se pueden morir de hambre" (Alicia). 
Gráfica 2

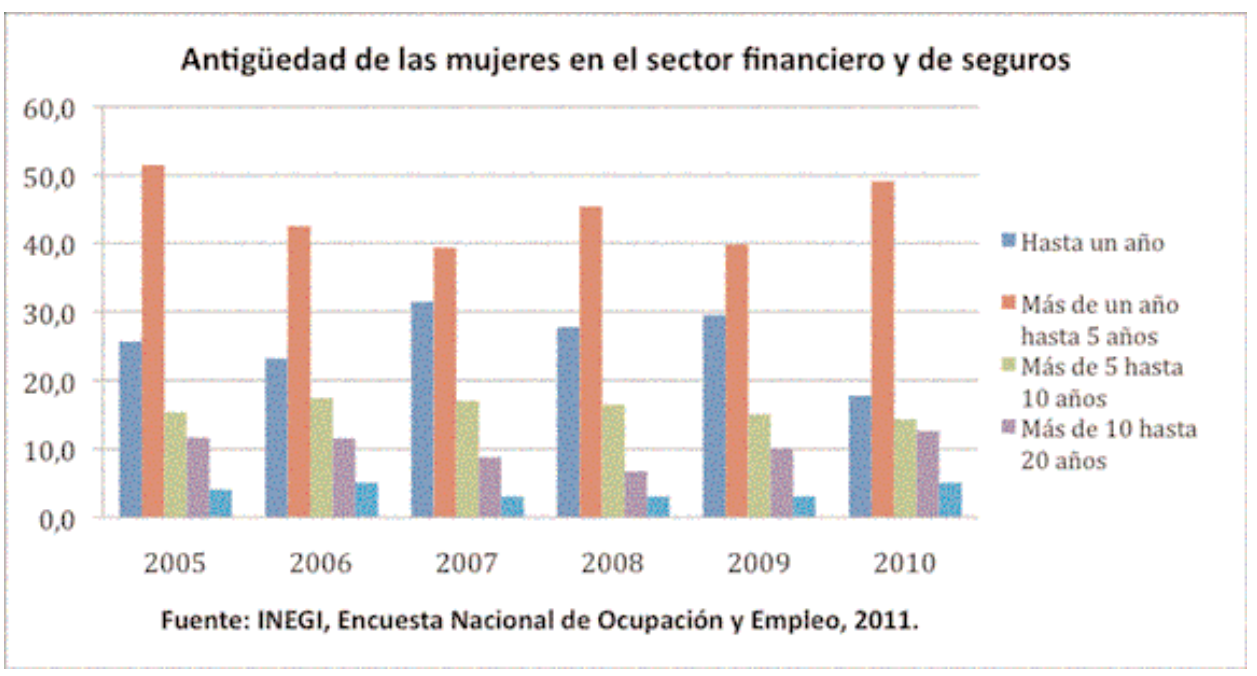

\section{SUBCONTRATACIÓN U OUTSOURCING}

Al estudiar las estadísticas sobre las formas de contratación, llama la atención que la mayoría de las empresas informen de la utilización del contrato escrito y muy poco el contrato oral. En 2010, dichas empleadas representaban el 83\% del total, porcentaje que parecía contradecir las afirmaciones de nuestras entrevistadas, cuando decían que existe una inestabilidad en el empleo en el sector financiero. El contrato por escrito sugería cuando menos cierta seguridad en el empleo.

Sin embargo, la realidad es otra, los contratos son temporales, aunque sean por escrito, no importa para fines de estabilidad laboral el tipo de contratación que se tenga. Para conocer la verdad habría que desglosar la información, saber si el trabajador/a es de base o temporal. Desgraciadamente, las estadísticas oficiales no muestran las series estadísticas con este nivel de desagregación. El único dato que nos acercaba a lo que realmente estaba sucediendo en el sector financiero era la antigüedad de las mujeres en el empleo. Si la mayoría tenían entre 1 y 5 años de permanencia no era posible que fueran de base, ni que tuvieran estabilidad laboral.

La respuesta estaba en otro lado, en una forma de contratación que se ha extendido por todo el mundo del trabajo y ha tomado fuerza en la banca, la subcontratación laboral o outsourcing. En ella, vieron las empresas la mejor manera de disminuir prestaciones y evitar las indemnizaciones por despido. La mano de obra ocupada en la banca redujo su costo y aumentaron las ganancias, es, pues, un negocio redondo, hace recaer sobre los trabajadores/as el peso de los cambios en el sistema financiero. 
Al principio, las labores de limpieza y mensajería, donde predominaban las mujeres, fueron trasladadas a empresas subcontratistas, con lo cual el personal termina su relación laboral con la banca aunque realice el mismo trabajo. Después, siguiendo el ejemplo de la banca española, pasaron al outsourcing a los empleados que se encargaban del desarrollo de aplicaciones informáticas, mantenimiento y soporte de equipos, la renovación de sistemas informáticos, de las comunicaciones, y de la explotación del centro de proceso de datos. Bajo el término financiero, el outsourcing se encarga de la gestión de letras y cheques y de la gestión de la bolsa y custodia de valores, hay muchas actividades más que pasaron a esa forma de subcontratación. (Sacristán, 2001: 6)

En México, este proceso de subcontratación empezó también por los empleados de limpieza y mantenimiento, se extendió a los administrativos y ahora se está implementando en las sucursales. Con respecto a lo sucedido a los empleados/as administrativos, Lucy, una de las entrevistadas, comenta:

"El banco comienza a liquidar gente y los recontrata otra empresa (outsourcing). Estos empleados no tienen seguro, perciben 5,000 pesos mensuales y promocionan los productos. Se sabe que existe otro proyecto, de liquidar ejecutivos y recontratarlos con un sueldo de 15,000 pesos mensuales, pero sin ninguna prestación”.

El avance del outsourcing se ha extendido a todo el sector financiero, unos bancos abarcando a todo el personal ocupado, otros sólo a los administrativos, pero todos con la idea de llegar a incluir a la totalidad de su personal. En el caso de los trabajadores administrativos, donde las mujeres son mayoría, según Lucrecia, empleada entrevistada, se han ido perdiendo prestaciones como el derecho a comedor y los 40 minutos que daban para la comer.

Por ejemplo, el líder sindical de los trabajadores de la banca, afirmó que BBVA Bancomer tiene a la totalidad de sus 27000 trabajadores en un prestadora de servicios (Bancomer Servicios), y aunque conservaron la mayoría de sus prestaciones, perdieron la posibilidad de recibir el reparto de utilidades.

"Bancomer es un ejemplo extremo para la cuestión del outsourcing, más 25 mil trabajadores, pero para Bancomer como una entidad, sólo trabaja una persona, los demás, están contratados por una empresa filial del banco, de suerte que cuando hay un reclamo laboral no es contra el grupo BBVA, es contra la empresa que presta este servicio de control de personal. Esto ya le quita gran parte de la responsabilidad al banco, de los deberes laborales, afirma un líder sindical de Bancomex”. ( Entrevista a Rafael)

De igual forma, Banco Azteca, Ahorro Famsa y Wal-Mart, entre otras instituciones bancarias tienen en outsourcing al total de su personal, ellos no respetaron sus derechos laborales. (México Laboral, 09/03/2009) 
El cuadro que a continuación presentamos muestra la magnitud del fenómeno de la subcontratación para el cual no existe casi límite alguno. Si los gobiernos de los principales países capitalistas son incapaces de regular al capital financiero, qué se puede esperar respecto a las condiciones de sus trabajadores/as.

\section{Cuadro 4}

\section{Personal contratado en la banca}

\begin{tabular}{|l|r|r|}
\hline Institución & Banca & Prestadora \\
\hline Bancomer & 0 & 27120 \\
\hline Banamex & 29831 & 0 \\
\hline Santander & 12334 & 1013 \\
\hline HSBC & 19018 & 2668 \\
\hline Inbursa & 0 & 1554 \\
\hline $\begin{array}{c}\text { Scotiabank } \\
\text { Inverlat }\end{array}$ & 8830 & 393 \\
\hline Azteca & 0 & 17994 \\
\hline Ahorra Famsa & 0 & 2232 \\
\hline Wall Mart & 0 & 307 \\
\hline Fuente: México Laboral, lunes 09/03/ 2009
\end{tabular}

El outsourcing es difícil de erradicar, aun cuando en México las leyes laborales establecen que los trabajadores tienen los mismos derechos sean subcontratados o no, el desempleo provoca que los trabajadores acepten el empleo incluso bajo condiciones negativas para ellos. También provoca que algunos de los dirigentes sindicales controlen el outsourcing por la vía de crear empresas de subcontratación de personal y ofrezcan sus servicios a los bancos.

Al no tener una relación directa con su banco- afirma Alfonso Bouzas- los trabajadores se ven limitados en sus derechos, algunos los conservan y otros los pierden. También puede darse el caso que con la prestadora de servicios conserven derechos como el reparto de utilidades, pero recordemos que legalmente ya no pertenecen a la empresa que genera las utilidades y por lo tanto, las prestaciones se negocian (Reforma, 9 de marzo de 2009).

Según nuestras entrevistadas, la subcontratación se aplica por igual a hombres y mujeres. Sin embargo, en el caso de ellas, se les contrata con salarios base más bajos y la posibilidad de ser despedida, -sin indemnización de acuerdo a la leyante cualquier falla ya sea por motivos laborales o familiares.

Si los sindicatos bancarios no manejan la contratación colectiva poco pueden hacer por sus agremiados, como bien dijo un dirigente, su labor está concentrada en evitar que cierren sucursales y más despedidos, todo lo demás no es prioritario. 
La banca además del outsourcing utiliza los llamados call center, cuyos empleados son los encargados de ofrecer tarjetas de crédito y otros servicios, se les paga según su rendimiento, se prefiere a mujeres en cierto tipo de servicios ya que las llamadas las pueden hacer desde su casa. Son controladas por computadora, además pueden ser grabadas y escuchadas por sus jefes. Debido a las condiciones que se padecen en este tipo de trabajo les pusieron el nombre de "electronic sweatshops". (Vega, 2009). Este tipo de empresas se han extendido tanto en la banca como en otro tipo de servicios, en general los trabajadores tienen peores condiciones que la empresa contratante, el salario esta en función de la productividad, tienen seguridad social (IMSS), pero no otras prestaciones que otorga el banco, sólo el call center de IXE pertenece a la empresa y sus empleados tienen iguales condiciones que los bancarios.

\section{NUEVAS FORMAS DE ORGANIZACIÓN DEL TRABAJO}

La aplicación de las nuevas tecnologías al interior de la banca ha reducido la dependencia de normas y compromisos de la era taylorista y desarrollado nuevas formas de organización del trabajo, las cuales podrían resumirse en la exigencia de un trabajador multifuncional, empleados más ligados a las ventas de servicios financieros, sustitución de directivos y supervisores por líderes de grupo y de gestión, promociones limitadas a las necesidades del grupo y la formación basada en la tecnología modular (Craig, 1996). Estas nuevas formas requieren un trabajador/a comprometido con la empresa, joven, sin gran experiencia laboral, dispuesto a aceptar cambios de horario, el no pago de horas extras y cambios en los sistemas de remuneración.

\section{CAMBIOS EN LA ORGANIZACIÓN DEL TRABAJO CON LA INTRODUC- CIÓN DE LA COMPUTACIÓN EN LA BANCA}

La aplicación de la computación a las actividades de la banca cambio para siempre su manera de trabajar, desaparecieron profesiones tanto en el área administrativa como en la operativa. En el área administrativa, las secretarias prácticamente desaparecieron. Las nuevas computadoras hicieron inútil ese trabajo, sólo quedaron las secretarias de los muy altos ejecutivos. Como la mayoría son mujeres seguramente formaron parte de las miles de personas despedidas durante los años ochenta. Realmente no se sabe hacia donde fueron a trabajar, porque las personas entrevistadas son jóvenes y no conocen como se llevó a cabo ese proceso.

Dentro de esta misma área, como podemos ver en el recuadro siguiente, se fusionan dos grandes categorías, ejecutivo de inversiones y promotor de ahorro e inversiones para pasar a ser solamente ejecutivo. Este es el gran cambio que mencionan nuestras entrevistadas, ya que acortó el tiempo de ascenso, de aprendizaje y de rendimiento, así como disminuyó las prestaciones y los salarios. El cambio llevaba 
implícito la aceptación de salarios según productividad, prolongación de la jornada y otro tipo de requisitos que a las mujeres se les dificultaba cumplir. Según Lucy:

"con la nueva organización, los puestos se recortaron, ya los chicos y chicas no asimilan los puestos como antes, entran directamente a ejecutivo porque antes era muy difícil ascender a ese puesto”.

Y agrega más adelante:

"la empresa misma ejerce coerción al obligar a los ejecutivos a no descansar para cumplir con la meta mensual y también, para realizar el cierre del ejercicio fiscal. Los domingos andas entregando tarjetas de crédito y no te pagan la gasolina, además tienes que utilizar tu carro que pasa a ser un instrumento de trabajo”.
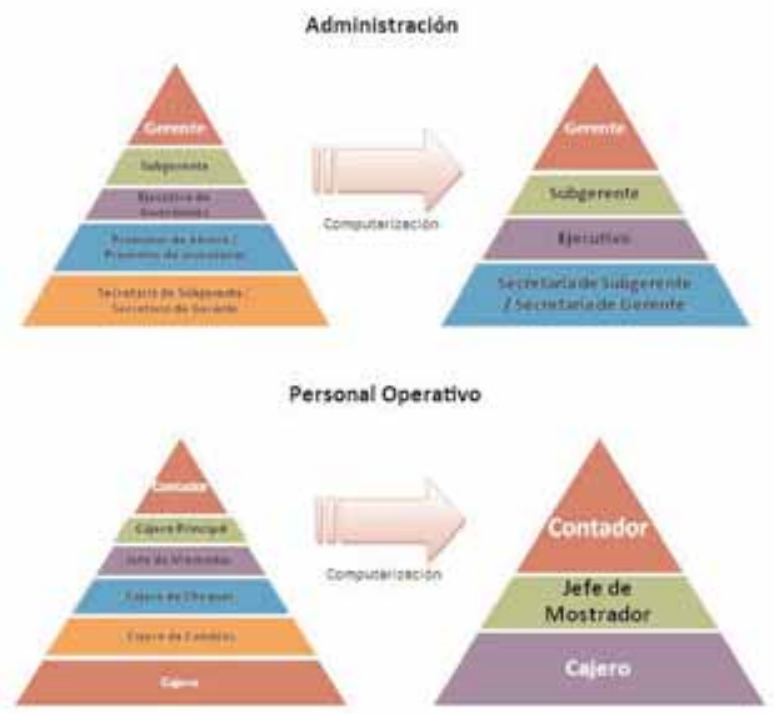

Fuente: Elaborado por Vianney Fernández con base en entrevistas a empleadas de la banca.

En el área operativa el impacto de la computarización fue todavía más grande, de seis categorías de trabajadores se redujeron a 3, quedando sólo el contador, jefe de mostrador y cajero. Con la nueva estructura el puesto de cajero a tiempo parcial desaparece. Ahora todos los empleados entran a una misma hora y a tiempo completo. La oportunidad de que a las cajeras se les otorgara tiempo parcial porque estudiaban o tenían hijos pequeños no existe. Las madres jóvenes tienen que buscar quién les cuide los niños.

La figura del cajero principal también desaparece porque ahora los recién ingresados al banco desempeñan esa función durante 3 meses. Lo cual representa un ahorro para el banco (Lucy).

En el caso de los ejecutivos, donde la participación de las mujeres ha ido cobrando importancia, la situación laboral sufrió varios cambios. La mayoría son 
solteras, algunas tienen hijos y son ayudadas por sus madres. Las cargas de trabajo son tan fuertes que laboran casi todo el día.

"Tu tiempo de descanso se recorta, las vacaciones disminuyen de 30 días hábiles a 5 o 3 porque si no cumples las metas no te pagan la comisión. Te obligan a ir a eventos del banco sin pago, de hecho ningún día de descanso laborado se les paga”. (Lucrecia)

Otros cambios importantes es que ahora las cajeras y los ejecutivos de cuenta realizan actividades muy semejantes, ambos tienen que vender seguros, tarjetas de crédito y otros servicios, lo cual va permitir que se eleve el rendimiento y obtengan un ingreso adicional a su salario, además hay un incremento en la productividad del trabajo.

Como hemos podido ver en la condición de la mujer se entrelazan una serie de factores que dificultan los ascensos en la carrera laboral, y por ende en mejores ingresos. Debido a la estrecha relación entre su desempeño laboral y el trabajo de cuidado, para la banca, aun la soltera en poco tiempo estará casará y tendrá hijos, por lo tanto, no pueden hacerse grandes planes de promoción y capacitación. Así, en 2010, tanto las mujeres casadas, $47 \%$ y las solteras $45 \%$ del total de mujeres ocupadas, enfrentarán una inequidad por su estado civil presente o futuro. Estas inequidades consisten en no ser tomadas en cuenta para promociones, por el simple hecho de ser mujeres y estar en condiciones de procrear. Como se exige jornada completa, se parte del supuesto que las mujeres con hijos no podrán cumplir con las exigencias que las nuevas formas de organización del trabajo requieren.

Las mujeres que trabajan de 35 a más de 48 horas a la semana, representaban en 2010 el 89\% del total de la población femenina ocupada; las jornadas menores, como ya vimos, carecen de importancia. Carolina, nos dice, "los cambios de horario fueron de 9.00 hrs. a 17hrs., pero de un tiempo para acá, el horario se ha extendido de 8 de la mañana a 7 de la noche, ni tiempo para comer, el trabajo es muy estresante"

El aumento en horas trabajadas de 2009 a 2010 es de llamar la atención, pasó de 62\% en 2009 a 69\% en 2010. Este hecho, nos dice dos cosas. Primero, las mujeres están trabajando muchas horas para no perder su empleo, tratan de rendir su máximo esfuerzo, superando a los hombres en las jornadas de tiempo completo. Segunda, sin importar que estén casadas o solteras, con hijos o sin ellos, las mujeres se enfrentan a una situación extrema, porque además de trabajar jornadas extenuantes tienen que atender hijos, cuidar ancianos, etc. El grupo social de estas trabajadoras les permite contratar empleadas domésticas o recurrir a la ayuda de la madre, hermanas u otros miembros de la familia. En esta crisis son las mujeres quienes están sacando a la familia adelante. 
Gráfica 3

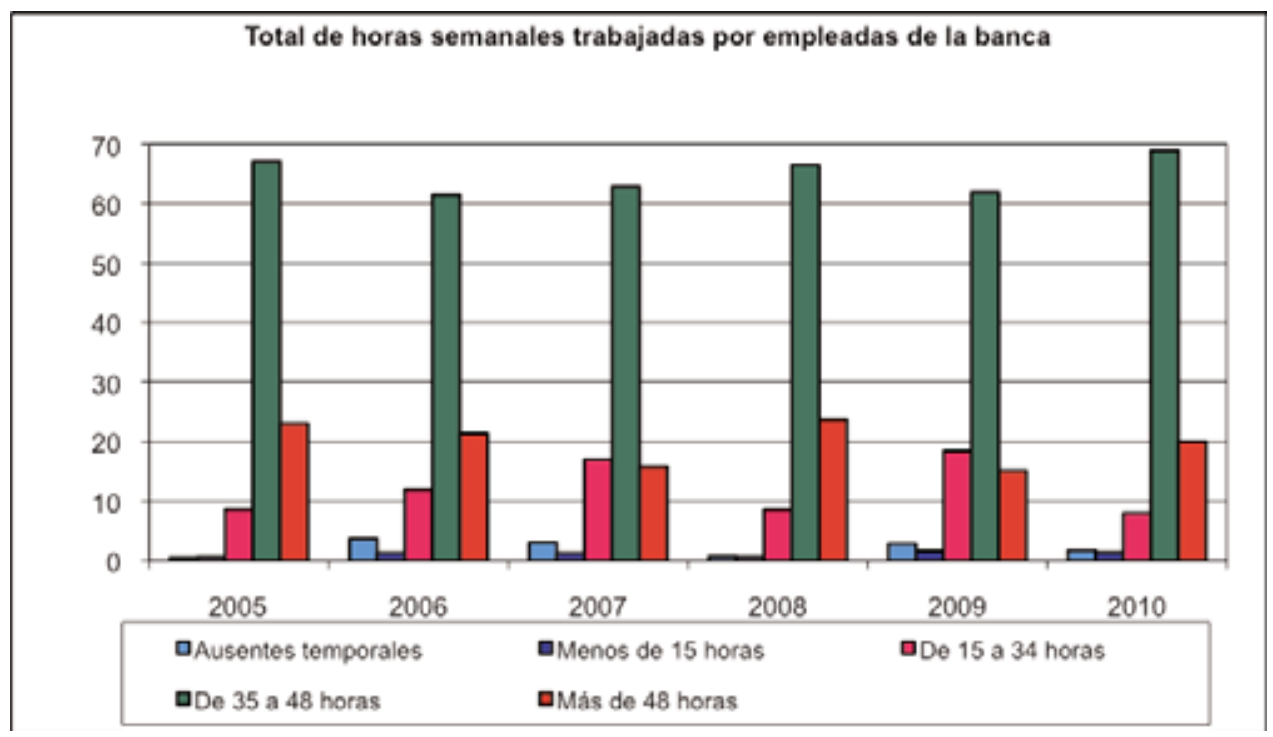

NIVEL SALARIAL

Los cambios en la forma de contratación afectaron los salarios de los trabajaras/es en la banca, los contratos se hacen por distinta duración, hay los que son por uno, tres o seis meses. El salario base para los nuevos es de alrededor de 5000 pesos (aproximadamente 357 dólares), más un bono de productividad cuya obtención depende del rendimiento en las tareas asignadas por el banco, en el mejor de los casos se puede alcanzar unos 7000 u 8000 pesos mensuales (Carolina). Este sistema de remuneración es sumamente ventajoso para la banca, porque se reducen las prestaciones al calcularse de acuerdo al salario base que aparece en el contrato.

En este sistema, el nivel salarial está en función del resultado de la evaluación del trabajo, los ingresos no son fijos pueden subir o bajar mensualmente. Los salarios fijos son ya casi artículo de museo. Los ingresos obtenidos por las primas en casi la mayoría de los casos representa la parte más importante del salario mensual. Bajo estas normas, el sindicato se debilita porque tiene poco que negociar en cuestiones salariales. Los sindicatos sobreviven sobre todo por las cajeras/os, son las que requieren más apoyo, por estar expuestas a fraudes, robos y otros tipos de ilícitos.

El nuevo sistema de remuneraciones tiende a perjudicar más a las mujeres, por su posición en puestos de menor categoría aunque de alta responsabilidad. Lo que no se corresponde con la resistencia de la empresa a otorgarles promociones. El argumento utilizado por un gerente de una sucursal para no dar una promoción a una cajera fue que ella tenía esposo y por tanto su ingreso no era tan importante para la familia: 
“En el caso de recibir alguna promoción, está implícito la obligación de trabajar más horas, varias compañeras que alcanzaron una promoción, pidieron regresar a su anterior puesto, porque no podían cumplir con sus responsabilidades familiares y el horario de trabajo era muy largo”. (Carolina).

Las mujeres que ascienden a ejecutivos de cuenta, gerentes de sucursal y otros más importantes, o son solteras o "tienen que sacrificar su vida familiar", porque en ellos, los permisos por maternidad, lactancia y enfermedades de los hijos están descartados.

“Las mujeres que logran llegar a puestos de dirección son mujeres dedicadas de tiempo completo al trabajo, para ellas la vieja pregunta si viven para trabajar o trabajan para vivir, queda resuelta porque viven para hacer una carrera, la llamada "vida personal” y el llamado "tiempo libre" no existen, su vida sólo tiene sentido en torno a su trabajo al cual se consagran en cuerpo y alma. Se convierte en su familia "Mi papá banca Santander” (Alba)

Las funcionarias para hacer una carrera profesional renuncian a la maternidad, prefieren el trabajo sobre la familia, entregan su vida a la organización para hacer una carrera hay una relación de incondicionalidad entre empleada y la empresa, tienen que invertir tiempo y energía para desarrollar estrategias para sobrevivir en este ambiente laboral, permanecen día, noche, fines de semana y días festivos si así lo exige la empresa y esto es lo que les da sentido a sus vidas. Estas trabajadoras "prefieren" no tener hijos para poder dedicarse al trabajo.

Según una de las empleadas entrevistadas, las cajeras tienen un trabajo de alta responsabilidad, ya que están expuestas a fraudes, robos y otro tipo de ilícitos realizados por los clientes o por los propios colegas. Los faltantes se descuentan de su sueldo.

Todas estas nuevas modalidades de las remuneraciones se reflejan en las estadísticas que aparecen sobre el nivel de las mujeres ocupadas en la banca.

Gráfica 4

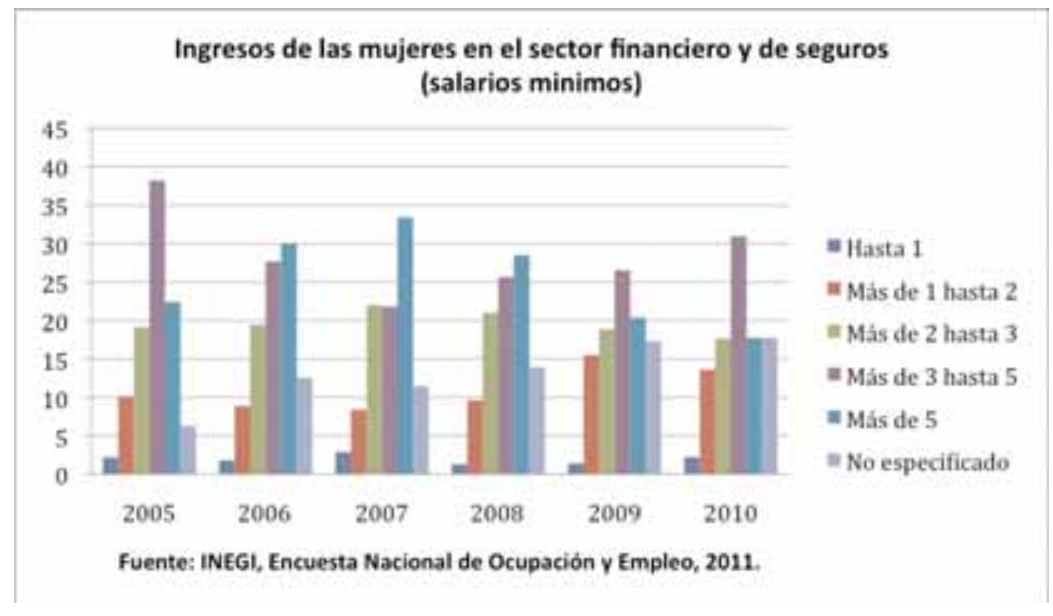


De acuerdo con la información de la gráfica.4., existe una tendencia a la disminución de las mujeres que ganan más de 5 sm de 2005 a 2010. El año mejor para ellas fue 2007, donde representaban el 39\% del total, pero la crisis provocó una reducción de las mujeres ubicadas en los niveles más altos de ingreso. La misma tendencia a la baja se observa en el rango de 3 a 5 sm, aunque en ella el movimiento se presentó con altas y bajas. Los hombres tampoco escapan al deterioro de sus ingresos pero no alcanzan el nivel de las mujeres.

Debido a que los ingresos de las mujeres están formados por el salario más el bono de productividad, se necesita la cooperación de todos los trabajadores de una sucursal. El bono depende del rendimiento general de todos los empleados, por lo cual unos y otros se presionan para alcanzar la meta trazada, si una falla, afecta a todos los demás. Por ejemplo, "Cada sucursal tiene una meta anual, si se rebasa en $25 \%$ la meta, el gerente del banco se puede llevar hasta 6 meses de sueldo, pero todo tienen que hacer un esfuerzo" (Lucy).

Los rendimientos de cajeros y ejecutivos también están entrelazados. Los cajeros contactan al cliente en la caja y le ofrece tarjetas de crédito y todo tipo de seguros: Si éste acepta, el ejecutivo hace la venta, habrá comisión para unos y otros. Existe una comisión por colocación de tarjetas, si se venden 10, la siguiente se paga a 500 pesos. Todas son formas de estimular al empleado/a a vender más a incrementar su productividad.

Por último, quisiera mencionar que estos cambios en las condiciones laborales van acompañados de tratos discriminatorios de jefes, colegas y clientes. Las mujeres se quejan de que son tratadas con bromas sexistas ofensivas por su modo de vestir, de hablar o por tener cuerpo de mujer. Sin embargo, cuando se pregunta si ellas han sufrido el acoso laboral, casi todas contestan que no, la vergüenza y el miedo a ser señalada como una empleada problemática es algo que todavía no pueden enfrentar.

Además se menosprecia su inteligencia, pues "cuando se trata de operaciones de poca monta a los clientes no les importa tratar con mujeres, cuando son grandes negocios prefieren a los hombres” (Claudia).

Los ingresos de las empleadas de la banca tienden a disminuir y al mismo tiempo las horas de trabajo aumentan, las prestaciones se recortan y los salarios dependen de la productividad, todo ello acompañado con la discriminación de genero, siguiendo la estrategia trazada de abaratar costos y aumentar las ganancia. En esta última crisis los bancos extranjeros que operan en México anunciaron altas utilidades para el sistema financiero en su conjunto. Utilidades que no provienen del crédito a las actividades productivas sino de las inversiones en el mercado de valores y en instrumentos especulativos, como es sabido por todos. 
Lo que está detrás de todo este problema es la incapacidad del neoliberalismo de crear empleos bien remunerados, invertir en actividades productivas y otras cosas más. El sistema neoliberal ha fallado, no tiene ya nada que ofrecer para sacar adelante a los países del estancamiento económico. Las bases de su existencia caducaron, su hijo predilecto el capital financiero no puede seguir siendo apoyado a costa de bajar el nivel de vida de la población. Para la clase trabajadora el impacto ha sido nefasto, las revueltas de los jóvenes en muchos países muestran el descontento y a ellos se suman nuevos grupos sociales de "indignados" y parece que nada cambia, la factura se pasa a los trabajadores y en una buena proporción a las mujeres.

Quiero reconocer el apoyo que me brindaron en la elaboración de este artículo a varias personas, sobre todo a Vianney Fernández Villagómez, Oyuky Marisol Calvo Briseño y Lilia Alejandra Becerril Aguilera. Además, agradecer especialmente a las trabajadoras entrevistadas su disposición a cooperar en este estudio.

\section{BIBLIOGRAFÍA}

CARCANHOLO, REINALDO A. y Paulo NAKATANI. (2001) Capital especulativo parasitario versus capital financiero. "Problemas del Desarrollo", vol. 32, num. 124, ene-marzo de 2001

CRAIG, Hill. (1996). Gestión de recursos humanos del sector financiero. http://www.comfia.net/index.php?pagweb=223

FISHER Eran.(2008) The classless workplace: the digeraty and the new spirit of technocapitalism. WorkingUSA. "The Journal of Labor and Society”, vol.11, June 2008 pp. 181-198

GONZÁLEZ, María Candelaria, Yajaira BRACHO de HERNANDEZ y Anais ALVAREZ (año). Nuevas características del trabajador bancario. Caso BANESCO Banco Universal, "Revista Venezolana de Gerencia”, Vol. 12 no.39, Maracaibo, sep. 200. pp 451 - 474.

International Labor Organization. Impact of Financial Crisis, “ Finance Sector Workers”, Geneve, 24-25 February 2009.

LICERAS, Dolores, Las mujeres en el mercado laboral actual (nuevas formas de organización del trabajo: ¿nuevas oportunidades para las mujeres?) "Cuadernos de Relaciones Laboras”, no. 6 Servicio de Publicaciones, Universidad Complutense, Madrid, 1995.

MAERTZ, Carl Jr., Jack W. WILEY, Cyinthia LeROUGE, and MICHAEL A.(2010) Campion. Downsizing Effects on Survivors: Layoffs, Offshoring, and Outsourcing, “Industrial Relations”, Vol. 49, No. 2 , Regents of the University of California.

MCDOWELL, Linda,.(2008):. Capital Culture: Gender al Work in the City. WyleyBlackwell, Chichester,

RICO IBAÑEZ, María Nieves y Flavia MARCO NAVARRO (2009): Privilegiadas y discriminadas. Las trabajadoras del sector financiero. Naciones Unidas, CEPAL. 
$M^{a}$ L. González Marín $\quad$ Cambios en la banca y su impacto en las empleadas del sector financiero...

SACRISTÁN NAVARRO, María (2001) Estado actual del outsourcing en el sector bancario, ICADE, "Revista de las Facultades de Derecho y Ciencias Económicas y Empresariales”, no.53, pp.249 - 295.

VEGA GARCIA, Alejandro 2009. Outsourcing y relaciones laborales y sindicales. El caso de BBVA-Bancomer, en http://www.omal.info/www/IMG/pdf/Outsourcing_caso_BBVA.pdf 